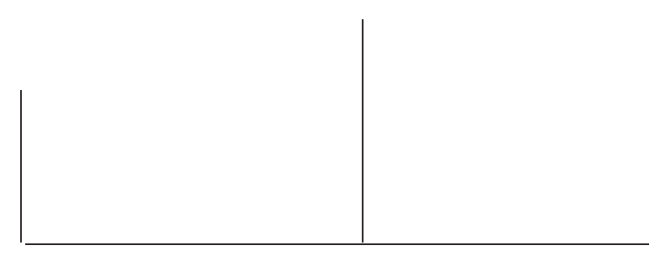

Rev. Latinoam. Psicopat. Fund., V, 4, 30-44

\title{
A compreensão freudiana da histeria como uma reformulação especulativa das psicopatologias*
}

Leopoldo Fulgencio

Este artigo pretende mostrar que, e como, Freud alterou a compreensão das psicopatologias da sua época, ao tomar como guia de pesquisa o ponto de vista dinâmico, enquanto um princípio metodológico especulativo de valor apenas heurístico.

Palavras-chave: Psicopatologia, histeria, especulação, dinâmica, heurística

* Neste artigo apresento um dos resultados (não incluído na dissertação) que obtive na pesquisa para a minha tese de doutorado $O$ método especulativo em Freud, PUC-SP, 2001. Essa pesquisa e seus resultados se inserem numa linha de investigação fundada a partir dos trabalhos de Zeljko Loparic, que tem sido desenvolvida, com resultados expressivos, pelo Grupo de Pesquisa em Filosofia e Práticas Psicoterápicas (GFPP) no Programa de Estudos Pós-Graduados em Psicologia Clínica da PUC-SP, tanto no que diz respeito à análise do lugar epistemológico e metodológico da psicanálise quanto no que se refere a uma revolução nessa disciplina, creditada a Winnicott (enquanto tendo desenvolvido uma psicanálise sem especulações, ou seja, sem a metapsicologia). Cf. uma lista dos resultados até agora obtidos e das pesquisas em andamento no site www.cle.unicamp.br/grupofpp. 


\section{ARTIGOS}

ano $V$, n. 4, dez/2002

A psicanálise começou tratando do problema dos sofrimentos neuróticos histéricos que o médico tentava diminuir ou eliminar, e não pela construção de um sistema teórico - seja empírico seja especulativo sobre a organização do psiquismo humano. Farei, aqui, um pequeno desenvolvimento histórico, que vai dos dados empíricos e das formulações da psiquiatria sobre a histeria, na época de Freud, até as principais formulações freudianas sobre esse problema. Será possível mostrar de que modo as formulações teóricas da psicanálise freudiana são exigências de solubilidade de problemas empíricos, apoiadas, no entanto, em concepções fundamentais especulativas que constituem a própria metapsicologia. Tratase, aqui, de buscar no texto de Freud a confirmação destas hipóteses, mostrando a presença e a inserção destes conceitos ficcionais que contribuíram para reformular o modo de compreensão das psicopatologias.

Quando jovem, Freud desejava manter-se no laboratório de fisiologia de Brücke, a quem "venerava acima de tudo" (Freud, 1925d, p. 58), até que, em 1882, o próprio Brücke o "exortara de forma incisiva, visto [sua] péssima situação material, a abandonar a carreira teórica" (Ibid., p. 58). Freud abandonará o instituto de fisiologia em junho de 1882, ingressando no Hospital Geral de Viena como aspirante, e, vagarosamente, afastar-seá dos problemas aos quais se dedicara até então, a saber, os relacionados à constituição anátomo-fisiológica do sistema nervoso. Entrando no Hospital Geral de Viena, Freud encontra doentes dos mais variados tipos, entre eles os psiquiátricos, que estão no serviço sob a direção de Meynert, "cuja obra e personalidade, ainda enquanto estudante, o tinham já cativado" (Ibid., p. 58).

A psiquiatria alemã considerava, grosso modo, que as doenças das quais se ocupava eram causadas por algum dano no sistema nervoso, constitucional ou devido a uma lesão ou a uma inflamação. É neste ambiente que Freud se forma e, como pesquisador, começa a se aproximar do problema das histerias. Nele encontra Breuer, que já era um médico extremamente bem-sucedido e de renome, que se torna para ele um amigo, conselheiro e protetor. Nesse momento, Freud, ainda residente de medicina, não tinha seu próprio consultório, mas Breuer tem pacientes histéricas, o que colaborou para aproximar Freud desse problema.

Após dois anos de trabalho junto aos doentes dos nervos no Hospital Geral de Viena, Freud resolve pedir uma bolsa para seguir seus estudos em Paris, junto a Charcot, no ano acadêmico de 1885-86. Para ele, o 


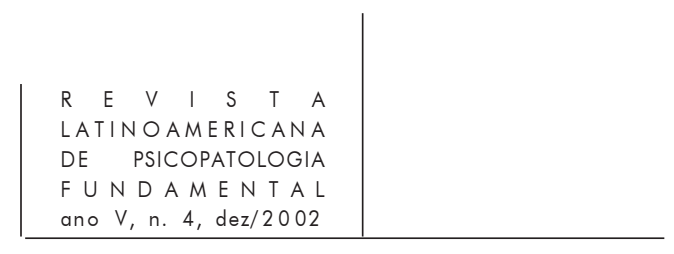

aprendizado numa universidade alemã chegara já a seu termo, enquanto que "a escola francesa de neuropatologia oferecia muito de novo e singular em sua modalidade de trabalho" (Freud, 1956 [1886], p. 5); mais ainda, a falta de diálogo efetivo entre a psiquiatria alemã e a francesa resultava num julgamento negativo das propostas de Charcot, o que ele via com reservas. É com tal quadro em mente que Freud resolve ver de perto o que o psiquiatra francês estava realizando: “... aproveitei com entusiasmo a oportunidade [de uma bolsa de estudos] que me era oferecida para formar, com minha própria experiência, um juízo fundado sobre as mencionadas séries de fatos". (Ibid., p. 5-6)

A passagem de Freud por Paris marcou uma virada na história da psicanálise, pois o colocou na rota do método de tratamento psicanalítico. O próprio Freud comenta o impacto que Charcot teve na sua vida intelectual:

Charcot, que é um dos maiores médicos cuja razão confirma o gênio, está simplesmente demolindo minhas concepções e meus planos. Aconteceu-me sair de seus cursos como se eu saísse de Notre-Dame, pleno de novas idéias sobre a perfeição. Mas ele me esgota e, quando eu o deixo, não tenho nenhuma vontade de trabalhar nos meus próprios trabalhos, tão insignificantes; eis três dias inteiros em que não tenho nada a fazer, e não sinto nenhum remorso. A semente produzirá seu fruto? Eu ignoro; mas o que sei é que nenhum homem teve tanta influência sobre mim. (Freud, 1960a, p. 197, carta de 24/11/1885)

Mas o que é que está sendo demolido? Em primeiro lugar, o reconhecimento de que a gênese da histeria não se deve, exclusivamente, a um fator biológico, mas sim a um fator psíquico; e, em segundo lugar, que há uma instância própria a idéias inconscientes, que são a causa desses distúrbios psicopatológicos, o que obriga, portanto, a não se considerar a consciência como sendo a totalidade de nossa vida anímica.

A história da medicina no século XIX concebe, inicialmente, a histeria não como um problema médico, mas moral. A histeria, com seus sintomas clássicos, não é propriamente uma doença, pois não há, nos exames, nenhum índice de lesão ou inflamação do sistema nervoso; trata-se, portanto, muito mais de um tipo de teatro ou fingimento, cujo objetivo é chamar a atenção, ou um pretexto para fugir das responsabilidades da vida, o que não constitui um problema médico, mas sim moral. No entanto, no correr desse século, algumas mudanças fundamentais tornam possível considerar a histeria como um problema médico. Em 1850, Paul Briquet (1796-1881) publica seu Traité clinique et thérapeutique de l'hystérie, em que define a histeria como "uma neurose do encéfalo cujos fenômenos aparentes consistem principalmente na perturbação dos atos vitais que servem à manifestação das sensações afetivas e das paixões" (Ellenberger, 1994 [1970], p. 174). Essa definição parece afastar aquilo que a história antiga da 


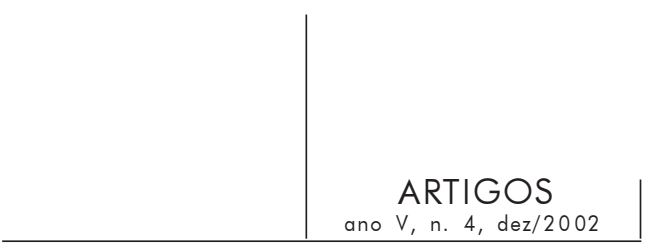

medicina vinha considerando como a base da histeria, ou seja, como sendo causada por desejos sexuais frustrados. Ao final do século XIX, encontramos também a defesa da hipótese de que a histeria é causada por uma cisão na personalidade do paciente.

Binet declarou em 1887: "Eu acredito que está suficientemente estabelecido o fato de que, de uma maneira geral, dois estados de consciência se ignorando mutuamente podem coexistir no espírito de um sujeito histérico". Em 1889, ele proclamava: "O problema que eu procuro resolver é o de compreender como e por que se instala nos sujeitos histéricos uma dissociação da consciência". (Ellenberger, 1994 [1970], p. 176)

A teoria que afirma estar a histeria relacionada com desejos sexuais frustrados jamais chegou a ser totalmente abandonada. Charcot irá se apoiar, mais tarde, nessas concepções de Briquet, recusando-se a reduzir a histeria a uma neurose sexual, ainda que reconhecesse que o componente sexual tinha um grande papel na vida de seus pacientes histéricos (Ibid., p. 175).

Quando Freud chega a Paris, a histeria já é um problema médico cuja gênese é atribuída à hereditariedade, às lesões ou inflamações do sistema nervoso que causam dano ou disfunção de seu funcionamento.

Charcot é, ao mesmo tempo, um clássico da neurologia do século XIX e um pesquisador que ultrapassa certos fundamentos básicos deste saber. Em primeiro lugar, deve-se lembrar que toda a tradição da medicina clínica dessa época tinha na "visibilidade" seu imperativo. ${ }^{1}$ Para que uma clínica fosse possível, era necessário que os sintomas pudessem ser visualizados e agrupados em entidades patológicas. Cabia ao médico um procedimento de observação para que os signos da doença pudessem ser apreendidos e destacados de um conjunto heterogêneo de sintomas, sendo possível, assim, identificar a forma mórbida na sua especificidade e, depois, procurar a sua etiologia.

Em 1893, Freud elogia a capacidade de Charcot de apreender formas clínicas novas, nomeando aquilo que até então era desconhecido, articulando a anatomia patológica à neuropatologia. Tratava-se, em Charcot, de tornar visíveis, em formas clínicas específicas, os sintomas e seus agrupamentos, tentando estabelecer a "localização" de uma lesão no sistema nervoso, fosse esta última tópica ou dinâmica. O que vai chamar a atenção de Freud é o olho clínico de Charcot associado à sua compreensão da histeria: "De tudo que eu vi com

1. Diz Foucault que "no início do século XIX, os médicos descreveram o que durante séculos permanecera abaixo do limiar do visível e do enunciável" (Foucault, 1977, p. X). Nesse texto, Foucault também comenta que esse "imperativo de visibilidade" é uma condição para o nascimento da clínica. 


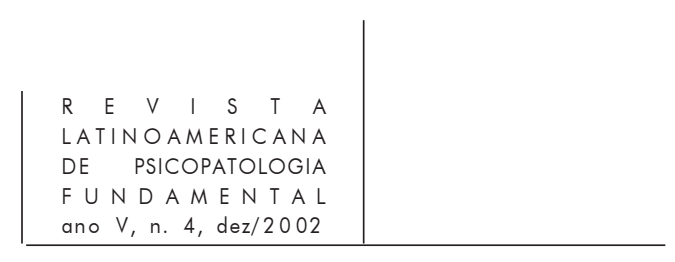

Charcot, o que produziu em mim maior impressão, foram suas últimas investigações sobre a histeria, que, aliás, em parte, foram efetuadas ainda sob meus olhos" (Freud, 1925d, p. 61).

Lembremos que Charcot procede, no Sapêtrière, à separação de quadros psicopatológicos: ele distingue os pacientes histéricos dos epilépticos, dando à histeria uma realidade clínica desprezada até então. A empreitada parece ser muito simples, e os critérios de diferenciação também. A princípio, os mesmos sintomas podem ser vistos tanto nos histéricos quanto nos epilépticos, mas os histéricos reagem ao que Charcot denominou "zonas histerógenas", ${ }^{2}$ o que não ocorreria nos epilépticos. Freud compara essa atitude de Charcot, em relação à histeria, ao ato libertador de Pinel em relação aos doentes mentais (Freud, 1893f, p. 69). Este proceder pôde fornecer uma nova realidade à histeria, dando ao saber um novo campo de trabalho e pesquisa:

[Charcot] tratou a histeria como sendo apenas mais um tópico da neuropatologia: forneceu a descrição completa de seus fenômenos, demonstrou que estes tinham suas próprias leis e regularidades, e mostrou como reconhecer os sintomas que possibilitam a feitura de um diagnóstico de histeria. (Freud, 1893f, p. 70)

Freud também ressalta que Charcot, por meio do uso da hipnose, pôde obter um avanço extremamente importante para a compreensão das paralisias histéricas, concluindo, "por meio de uma sólida cadeia de argumentos, que essas paralisias eram o resultado de idéias que tinham dominado o cérebro do paciente em momentos de disposição especial" (Ibid., p. 72). O mecanismo de um fenômeno histérico era, assim, análogo ao que ocorre na sugestão hipnótica, no caso em que o hipnotizado executa, fora do estado hipnótico, uma ordem dada pelo hipnotizador sem, no entanto, ter tal ordem presente na sua consciência.

Em Charcot, trata-se de ver e descrever. "Não era alguém que ruminasse, nem um pensador, mas uma natureza artisticamente dotada, segundo seus próprios termos um visuel,* um homem que vê" (Ibid., p. 62). Quando Freud propõe a Charcot um trabalho em conjunto, em que as paralisias orgânicas seriam comparadas com as histerias, ele logo percebe que Charcot não tinha muito interesse pela psicologia: “... era fácil ver que, no fundo, ele não tinha nenhuma predileção particular para entrar mais profundamente na psicologia das neuroses" (Freud, 1925d, p. 62-3). O que pode significar que Charcot mantinha-se fiel a uma prática que visava uma certa fenomenologia clínica, e que isto lhe parecia

2. São lugares hipersensíveis do corpo, cuja estimulação leve desencadeia um ataque (cf. Freud, 1888b, p. 47).

* Em francês no texto. 


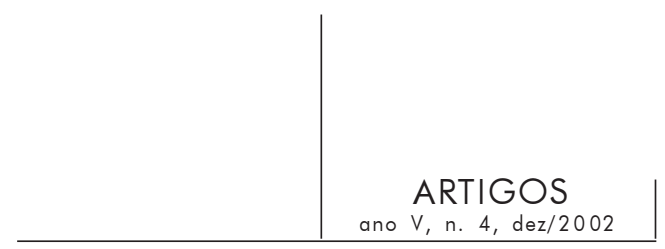

tanto necessário quanto suficiente para o entendimento das patologias, o que justifica que ele não tivesse a necessidade de uma teoria, em termos psicológicos, para entender os sintomas.

Com Charcot, Freud aprenderá a ver o problema por outro ângulo, ou melhor, um novo problema, e é justamente esse "novo problema", baseado em certos princípios básicos, que dará a via a ser percorrida até a descoberta do método psicanalítico de pesquisa e cura. Charcot mostra, retomando o uso da hipnose, que é possível, por sugestão hipnótica, eliminar ou introduzir sintomas nos pacientes histéricos. Resumidamente, pode-se dizer que ele tem dois pressupostos novos: primeiro que a causa da doença não é exclusivamente orgânica, havendo uma causa psíquica fundamental para o surgimento da doença; segundo, que essa causa é um acontecimento traumático que provoca um tipo de cisão no psiquismo do paciente, deixando as idéias presentes no momento do trauma (as idéias traumáticas) num estado inconsciente para o sujeito, ou seja, partindo seu psiquismo em duas partes igualmente ativas, a parte consciente, que nada sabe dessas idéias, e a parte inconsciente que, devido à cisão, produz os sintomas histéricos. Para que isto ocorra, é necessário certa predisposição do paciente, seja em termos hereditários, seja por algum outro tipo de distúrbio (físico) no sistema nervoso. Assim, Freud aprende a ver, na histeria, a presença de dois tipos de idéias - conscientes e inconscientes - que têm, justamente nesta cisão, a causa psicogênica dos sintomas histéricos.

Charcot mantém-se como um empirista, limitando-se aos aspectos descritivos dos fenômenos. Sua adesão à neurofisiologia - como referente último que explica os distúrbios psicopatológicos - o insere num ponto de vista que podemos caracterizar como estático ou mecânico: acontece o problema da patologia histérica porque, por ocasião de um trauma, ocorreu uma cisão da consciência, ou seja, uma quebra que desarticulou a rede de conexões das idéias, tal como um boneco que não move o braço porque tem uma articulação quebrada. A suposição é de que essa quebra ocorre porque há uma debilidade do sistema ou das "articulações". A cura seria encontrada desde que fosse refeita ou reestabelecida a articulação danificada. Ou seja, em última instância, tratar-se-ia de um problema mecânico.

Em Janet, que prosseguiu, em certo sentido, a pesquisa dos fenômenos neuróticos na mesma direção de Charcot, ocorre o mesmo tipo de explicação (cf. Ellenberger, 1994 [1970]). Suas teses sobre a debilidade (adquirida ou hereditária) da "função do real" como fundo de toda neurose, e sua concepção do inconsciente enquanto parte cindida do psiquismo, continuam a referir o problema das histerias a uma questão, em última instância, de anátomo-fisiologia.

Aqui reside uma das diferenças capitais entre as propostas de Freud e a de Charcot. Face aos mesmos dados empíricos observáveis - sintomas sem causa 


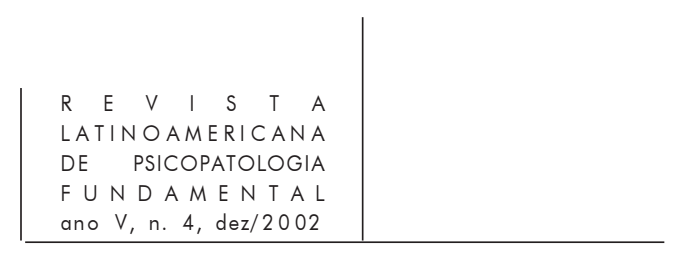

orgânica reconhecível diretamente, reconhecimento de idéias conscientes e inconscientes, constatação da ocorrência de traumas etc. -, dois pontos de vista díspares poderiam ser propostos. Como estamos mostrando, Charcot compreende a histeria dentro do quadro de uma neurofisiologia estática, considerando o sintoma como fruto de uma desarticulação mecânica que resulta numa cisão entre grupos de representações. Num organismo débil, com falhas de ordem biológica, ocorre uma quebra no psiquismo, constituindo pensamentos (conjunto de representações) que funcionam de maneira desarticulada, resultando, portanto, em sintomas. Para Freud, a situação é outra; ainda que não esteja afastado totalmente o reconhecimento desse fundo biológico como base orgânica para a constituição dessa patologia, ele não pensa a histeria em termos estáticos; para ele, os sintomas não são um fruto da cisão mecânica entre representações, mas do conflito entre elas: a oposição entre o conjunto de representações que caracterizam o "eu" e um outro conjunto que se opõe a estas (representações inconciliáveis com o "eu"). Trata-se de uma concepção dinâmica que admite forças psíquicas em conflito (Freud, 1913m, p. 29-30).

Como sabemos, não é apenas de Charcot que Freud retira sua compreensão dos neuróticos e dos meios usados para tratá-los. A referência à hipnose e à histeria também nos leva a outras contribuições. De Charcot, Freud aprende a ver "as diversas formas de suas [dos ataques histéricos] manifestações em fórmulas descritivas" (Freud, 1913j, p. 195), compreendendo o mecanismo de funcionamento da histeria traumática como efeito de uma divisão da consciência; de Liébault e Bernheim, figuras maiores da escola de Nancy (psiquiatria francesa), aprende a eficácia da sugestão, com ou sem hipnose, como instrumento terapêutico (Freud, 1925d, p. 64-5); de Janet, a descrição e a evidência dos processos mentais inconscientes; e, de Breuer, não só o reconhecimento "das representações inconscientes que agem por trás dos ataques [histéricos] (Freud, 1913 j, p. 195), mas também o desvelamento do procedimento catártico como modo de pesquisa da etiologia e da cura dos sintomas histéricos.

O abandono da hipnose e do método catártico, a favor da utilização do dispositivo analítico da associação livre e do divã, significa a fundação da técnica analítica. ${ }^{3}$ Este ato envolve uma nova compreensão da patologia

3. Mesmo tendo renunciado à hipnose, em função de seus magros resultados clínicos, Freud reconhece que nela age o processo afetivo básico que sustenta o próprio tratamento analítico, que ele nomeará de transferência, reconhecendo o poder de influência que o médico tem sobre o seu paciente. Ele reconhece também, no entanto, que a transferência e sua análise não fornecem os mesmos efeitos imediatos que a hipnose fornecia, o que não significa manter a hipnose como instrumento analítico: "É sem dúvida desejável abreviar a duração de uma cura analítica, mas a via para atingir nosso objetivo terapêutico se faz sempre passar pelo aumento 


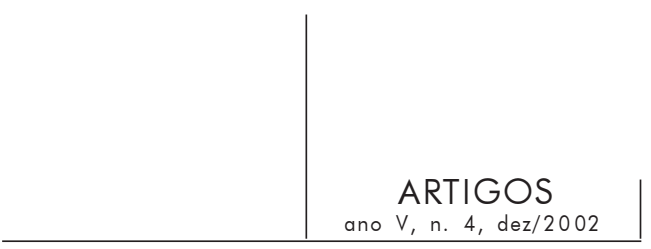

histérica ${ }^{4}$ que abandona a visão neuro e anátomo-patológica da época, apresentando um novo método de tratamento. Para realizar essa nova proposta de tratamento psíquico, é necessário que Freud faça conjugar diversas concepções, a saber: 1) o sintoma histérico pode ser explicado em função de sua origem psicoafetiva, ainda que não seja descartada a necessidade de que exista um organismo (biológico) predisposto a ser assim afetado, é aos fatores de ordem psíquica que a psicanálise credita a gênese desses sintomas; 2) esses têm uma estrutura análoga às sugestões pós-hipnóticas, e devem, portanto, ser considerados como efeitos de representações psíquicas inconscientes; 3) o tratamento por sugestão hipnótica está baseado na relação que o paciente tem com o médico e é este o fundamento que explica as curas obtidas por esse método, ou seja, o reconhecimento do fenômeno da transferência; 4) o uso do método hipnótico, além de não ser lá muito eficaz, escamoteia o verdadeiro motor do processo de cura que se obtinha por meio da hipnose e do método catártico, a saber: a transferência.

Podemos, assim, compreender o afastamento que Freud realiza face ao paradigma neuroanatômico, de localização estrita ou disfunção, para a explicação das histerias. Em vez de considerar a histeria como sendo fruto de uma degeneração do sistema nervoso, na qual a hereditariedade congênita tem papel central, e cujo resultado seria uma dissociação psíquica entre idéias conscientes e inconscientes, Freud dirá que a psicanálise

... propõe, no lugar de uma simples descrição, uma explicação dinâmica fundada na interação de forças psíquicas, e atribui a origem da dissociação psíquica (cuja importância tinha sido igualmente reconhecida por Janet) não à [um fracasso da] síntese mental resultante da incapacidade congenital, mas a um processo psíquico particular conhecido pelo nome de "recalque". (Freud, 1913m, p. 29-30; grifos meus)

da força de sustentação do eu que nós queremos trazer ao eu. A influência hipnótica parecia ser um excelente meio para atingir nossos fins; sabemos porque renunciamos a ela. Até hoje não foi encontrado um substituto para a hipnose, mas compreende-se, desse ponto de vista, os esforços terapêuticos, infelizmente infrutíferos, aos quais um mestre da análise como Ferenczi consagrou os últimos anos de sua vida" (Freud, 1937c, p. 245). Cf. Fulgencio (1998) para uma análise sobre esse tema.

4. Cabe aqui lembrar que fazia parte da prática médica psiquiátrica do final do século XIX a escolha de uma patologia específica como paradigma para as outras patologias nervosas. É o caso da "Síndrome de incorporação motora" de Gilles de la Tourette, da "Dementia Praecox" de Kraepelin, da "Esquizofrenia" de Breuler; e também será a histeria e a neurose obsessiva com Freud, como comenta Mezan ao falar do desenvolvimento dos paradigmas na psicanálise (cf. Mezan, 1998, p. 122 e 127). 


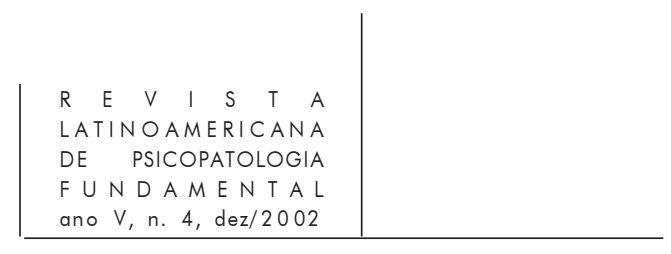

É importante entender, na compreensão do ponto de vista de Freud, que ele encontrou, em Charcot e contra Charcot, os ensinamentos que o obrigaram a abandonar um modo de ver as coisas e a estabelecer um novo rumo para o pensamento, dando a ver um outro universo a ser observado, com outros dados a serem organizados e relacionados. Os resultados de uma mudança de tal monta foram lentamente sentidos.

Voltando a Viena, no outono de 1886, Freud se estabelece como médico, e também se dedica, juntamente com o pediatra Kassowitz, ao tratamento de doenças nervosas de crianças num instituto público. Seu arsenal terapêutico era composto de apenas duas armas, a eletroterapia e a hipnose, sendo que a primeira, sem nenhuma eficiência, mostrava-se muito mais uma obra da fantasia do que um método científico, enquanto que a hipnose oferecia algum resultado prático. A preocupação com o tratamento das histerias continua e o intercâmbio com Breuer também. Não é necessário seguir, passo a passo, as atividades de Freud, mas tão-somente focar dois problemas clínicos centrais que ele tenta resolver: o das afasias e o das histerias. Quanto ao primeiro, suas pesquisas resultarão numa crítica aos pontos de vista estritamente anatômicos de Wernicke-Lichteim, em favor de uma concepção da patologia como um distúrbio funcional sem a necessidade de considerar alguma lesão do sistema nervoso.

Em 1888, quando Freud escreve o verbete Histeria para um dicionário de medicina geral, ele ainda a apresenta muito mais como uma "anomalia constitucional do que como uma afecção produzida" (Freud, 1888b, p. 57). A terapia consiste, pelo lado profilático, em tentar evitar, num paciente com predisposição histérica, a manifestação da doença. Por isso, deve-se "desaconselhar que [o paciente com predisposição] submeta seu sistema nervoso a trabalhos excessivos, tratar a anemia [...] e, por último, reduzir o significado dos sintomas histéricos leves" (Ibid., p. 62). Por outro lado, o tratamento dos sintomas histéricos efetivos, para os quais o método catártico de Breuer é o mais eficaz, "consiste em reconduzir o enfermo, hipnotizado, à pré-história psíquica do padecer, levando-o a confessar, na ocasião psíquica, a raiz da qual se gerou a perturbação correspondente. Este método terapêutico é bem recente, mas tem mostrado êxitos terapêuticos que não se encontra de outro modo" (Ibid.).

Com o uso da sugestão hipnótica, é possível tentar tratar esses doentes. A princípio apenas por meio sugestivo, ordenando o desaparecimento dos sintomas; depois, com o reconhecimento do trauma e da cisão que ele produziu no sujeito, faz-se uso da sugestão hipnótica para que o paciente possa trazer para a consciência as idéias que foram dela afastadas e que causam os sintomas.

Esta concepção difere da posição de Charcot, pois a questão não é mais a de uma cisão que basta ser refeita, como um braço ou uma articulação quebrada 


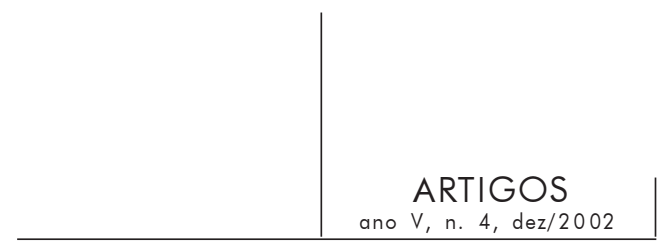

que impossibilita um movimento. O sintoma histérico, reconhecidamente causado por um trauma de ordem psíquica, estabelece um conflito entre as idéias conscientes e as inconscientes, e é justamente esse conflito que produz o sintoma, e não a falta de articulação entre as partes.

O que se transformou, em termos básicos, é que Freud substituiu o ponto de vista mecanicista pelo dinâmico, substituiu o princípio causal responsável, em última instância, pela própria existência dos sintomas. $\mathrm{O}$ reconhecimento dos conflitos, enquanto parte dos dados descritivos que a observação clínica fornece, poderia ser explicado tanto em função de um ponto de vista como de outro. Poder-se-ia ver o conflito como um suposto efeito de partes de um sujeito cindido, funcionando desconexas ou desarticuladas (ponto de vista mecânico); mas o conflito pode também ser entendido como causado por forças (ou conjunto de representações carregadas de afetos, que constituem forças psíquicas) em oposição. A escolha pela perspectiva dinâmica, como base para explicar o conflito e o sintoma, corresponde a um tipo de pressuposição ou de princípio a priori que a experiência não tem condições de provar, nem como falso nem como verdadeiro, mas tão-somente como eficaz ou não, correto ou incorreto, para fornecer organização e transparência na apreensão dos fenômenos e na explicação de suas relações de co-determinação.

A suposição da existência de forças psíquicas em conflito no interior de um mesmo psiquismo, responsáveis, na sua composição, pela produção dos sintomas, não deriva diretamente da observação. Que conflitos sejam reconhecíveis não significa que forças psíquicas sejam dados empíricos. A história da física já mostrou o caráter especulativo da noção de força. A concepção de forças psíquicas como sendo a causa dos fenômenos psíquicos é uma analogia cuja eficiência, para Freud, justifica o uso. A opção metodológica pela procura de forças para explicar os fenômenos da natureza, incluindo o homem, corresponde a uma especulação metodológica bem anterior a Freud. Sua formação junto a Brücke nos faz lembrar um princípio metodológico de pesquisa ditado por Brücke e Du-Bois Reymond e retomado por Freud, à sua maneira:

Brücke e eu [Du-Boys Reymond] nos comprometeremos a impor esta verdade, a saber, que somente as forças físicas e químicas, com exclusão de qualquer outra, agem no organismo. Nos casos que não podem ser explicados, no momento, por essas forças, deve-se empenhar em descobrir o modo específico ou a fonte de sua ação, utilizando o método físico-matemático, ou então postular a existência de outras forças equivalentes, em dignidade, às forças físicoquímicas inerentes à matéria, redutíveis à força de atração e repulsão. ${ }^{5}$

5. Du-Bois Reymond, citado por Shakow \& Rapaport (1964, p. 34). 


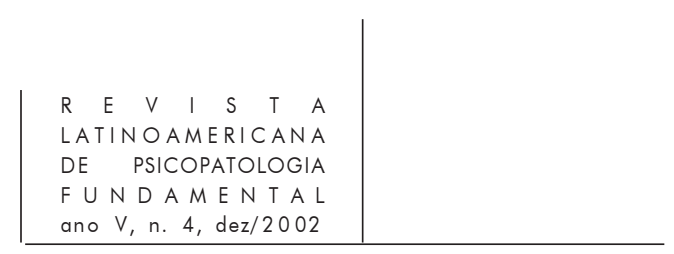

É justamente nesse sentido que Freud postulará as pulsões: ${ }^{6}$ forças psíquicas, equivalentes em dignidade às forças físico-químicas. O percurso que vai da visibilidade empírica, proposta por Charcot, até a formulação do primeiro dualismo pulsional, proposto por Freud, pode ser aqui rapidamente esboçado. Freud observou, na escuta de seus pacientes em sugestão hipnótica, que o trauma procurado era invariavelmente de origem sexual e ocorrido na infância, o que o levou a elaborar sua teoria sobre as histerias baseado num acontecimento factual: a sedução. O decorrer de suas pesquisas mostraram-lhe duas coisas fundamentais: primeiro, que o abuso sexual factual lembrado remetia a momentos infantis remotos, fazendo-o supor a existência de uma sexualidade infantil, ou seja, levando-o a conceber a sexualidade num sentido muito mais amplo; segundo, ele percebeu que suas histéricas mentiam, que elas contavam fatos fantasiados como se fossem reais, o que o obrigou a abandonar a sua neurótica ${ }^{7}$ (sua teoria sobre as neuroses baseada na sedução real) e a propor a noção de fantasia. Como as fantasias dos pacientes se apresentavam como tendo o mesmo poder dos acontecimentos reais, tanto um como outro teriam a capacidade de produzir traumas psíquicos. Assim, Freud foi obrigado a conceber o conflito, causa do sintoma, como um problema produzido no interior do psiquismo. Se antes tínhamos um conflito sexual entre um desejo adulto e um sentimento infantil, agora temos, um interesse sexual interno que parece atacar o próprio paciente. No desenvolvimento futuro da psicanálise, Freud postulará a existência nos neuróticos (cujo modelo é a histeria) de duas pulsões que se colocam em conflito: a pulsão sexual e a de autoconservação.

Ao supor um inconsciente movido por pulsões em conflito, Freud ultrapassou o nível puramente descritivo dos fatos, acrescentando-lhes especulações dinâmicas. Uma coisa é admitir a existência do inconsciente como uma instância diferente da consciência, fato comprovável empiricamente, por exemplo, pela análise dos atos falhos, outra, totalmente diferente, é supor que o inconsciente é animado por forças e energias psíquicas. ${ }^{8}$

Mas por que Freud especula? Ele diz claramente ter passado "da apresentação descritiva à concepção dinâmica" (Freud, 1916-17, p. 400), pois considera que a psicologia que se mantém apenas nesse nível descritivo - ou

6. Cf. uma análise sobre o conceito de pulsão na história da filosofia em relação com a da psicanálise em Loparic (1999).

7. Cf. carta de Freud a Fliess de 21 de setembro de 1987.

8. Uma análise dessa diferença entre um inconsciente descritivo, admitido como fato, e um inconsciente dinâmico, construído especulativamente, pode ser reconhecida na comparação entre as propostas metapsicológicas de Theodor Lipps e as de Freud. Cf. Lipps 2001 [1897] e Loparic 2001b. 


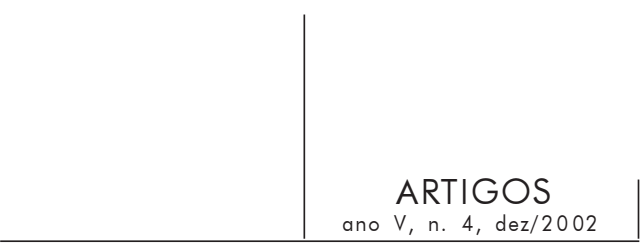

noutros termos, apenas no campo da consciência -, jamais obterá uma explicação completa da série de determinações causais que produzem os fenômenos psíquicos. No entanto, ao considerar um inconsciente movido por pulsões, enquanto causas últimas atrás das quais nada de anterior deve ser suposto, ele pode fornecer essa explicação:

Enquanto a psicologia da consciência não pode jamais sair destas séries lacunares e depende manifestamente de outra coisa, a concepção a partir da qual o psíquico é em si inconsciente permitiu fazer da psicologia uma parte, semelhante a todas as outras, das ciências naturais. (Freud, 1940a, p. 20-1)

A atitude especulativa de Freud está em função da procura da solução de problemas empíricos, ou, noutros termos, de problemas clínicos. Até mesmo o conceito mais especulativo da psicanálise freudiana, a pulsão de morte, foi elaborado na tentativa de explicar a produção de certos fenômenos psíquicos observáveis nos tratamentos psicanalíticos:

... não é por causa dos ensinamentos da história e da experiência da vida que nós preconizamos a hipótese de uma pulsão de agressão e de destruição particular no ser humano, mas isto se fez sobre a base de considerações gerais às quais nos conduz a apreciação dos fenômenos do sadismo e do masoquismo. (Freud, 1933a, p. 187)

Cabe, então, a pergunta: que valor Freud dá às suas especulações dinâmicas? Ele as considera como hipóteses a serem comprovadas futuramente, quando o desenvolvimento da sua ciência, e da ciência em geral, chegar a um ponto no qual seria possível estabelecer claramente seu referente empírico? Ou ele as toma como construções auxiliares, especulativas na sua própria natureza, no entanto úteis, pois tornam possível operar sobre os dados empíricos? A segunda hipótese parece mais de acordo com o texto de Freud. Basta retomarmos seus comentários epistemológicos, no início do "Pulsões e seus destinos", para vermos que ele não considera a pulsão como um conceito empírico, mas como um "conceito fundamental convencional, provisoriamente ainda muito obscuro, mas que nós não podemos dispensar em psicologia" (Freud, 1915c, p. 164), como uma idéia abstrata (Ibid.) que se aplica ao material empírico:

Inicialmente, elas [essas idéias abstratas] devem comportar um certo grau de indeterminação; não se pode pensar em discernir com clareza seu conteúdo. Enquanto se encontram nesse estado, temos que nos pôr de acordo sobre seu significado para remetê-las repetidamente ao material empírico do qual parecem ter sido extraídas, mas que, na verdade, lhe é submisso. Com todo rigor, elas têm, então, o caráter de convenções, ainda que tudo dependa do fato de que elas não são escolhidas arbitrariamente, mas, ao contrário, estão determinadas por relações significativas com o material empírico, relações que acredita-se poder 


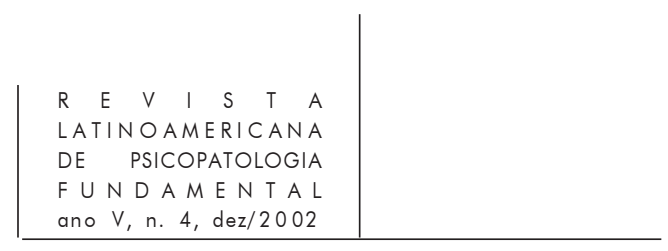

advinhá-las antes mesmo de poder reconhecê-las e demonstrá-las. (Freud, 1915c, p. 163)

Para Freud, o ponto de vista dinâmico está fundado sobre uma mitologia das pulsões (Freud, 1933a, p. 178), quer dizer, sobre um conceito que é um mito e, como todo mito, indecidível empiricamente. O objetivo dessa ficção teórica não é oferecer uma hipótese que se espera verificável futuramente como verdadeira ou falsa - em função de sua correspondência com um referente na realidade objetiva dos fatos -, mas sim de ser útil para fornecer uma explicação e/ou resolução dos problemas aos quais se aplica e, nesse sentido, tornar possível agir sobre eles. Ou seja, essa especulação tem, para Freud, um valor apenas heurístico e não um valor objetivo (empírico).

Isso não constitui uma inovação na história da ciência, mas a reiteração de uma determinada metodologia de pesquisa, claramente reconhecível em diversos cientistas do século XIX, importantes para a formação de Freud, tais como Fechner, Helmholtz, Brück. Ao retomarmos alguns estudos atuais que interpretam Mach como um clássico do ponto de vista heurístico (Loparic, 1984), podemos reconhecer uma proximidade metodológica entre ele e Freud. ${ }^{9}$ Basta para isto, como índice significativo dessa proximidade, lembrar as palavras de Mach, que parecem ter sido retomadas por Freud, quando ele disse, ao analisar a física de seu tempo, que ela estava apoiada numa "mitologia dinâmica" (Mach, 1905, p. 313). ${ }^{10}$

Essa perspectiva de leitura, que coloca Freud como defensor do ponto de vista heurístico na prática científica, incita a fazer uma distinção entre a psicologia freudiana dos fatos clínicos (psicologia descritiva) e a sua metapsicologia (enquanto conjunto de especulações teóricas cuja finalidade é descobrir soluções para os problemas próprios aos domínios da psicanálise). O próprio desenvolvimento da metapsicologia, tanto em Freud como nos pós-freudianos, poderia ser analisada nessa perspectiva, recolocando os problemas na frente das teorias. Nessa mesma direção cabe, então, reconhecer, partindo dos dados aqui analisados - como indicadores da atitude metodológica de Freud -, que ele reformulou a compreensão das psicopatologias por meio de certas especulações (pulsões, aparelho psíquico dividido em instâncias, libido etc.), dado que são as

9. Freud assina um documento intitulado "Convocação para a fundação de uma Sociedade para a Filosofia Positivista", junto com Mach, em 1911, indicativo de sua adesão ao ponto de vista heurístico (Cf. Fulgencio, 2001a).

10. A compreensão da origem desse tipo de escolha metodológica de pesquisa pediria que nos remetêssemos não só a uma análise mais profunda de Mach, como também exigiria compreender o programa de pesquisa kantiano apresentado na Crítica da razão pura. O que está feito em Fulgencio (2001b). 


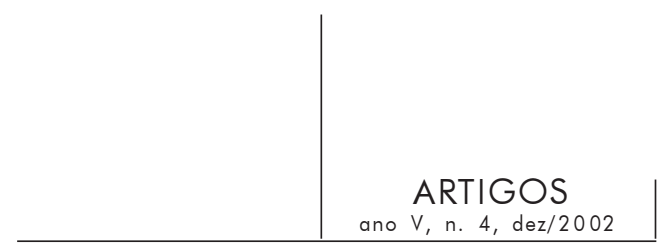

explicações metapsicológicas e não os dados descritivos que fornecem a explicação causal das séries de determinações que produzem esses fenômenos. Face, então, aos problemas que a psicanálise tenta resolver caberia a pergunta atual, sobre o lugar e a necessidade da própria metapsicologia.

\section{Referências}

Ellenberger, H. F. (1970). Histoire de la découverte de l'inconscient. Mesnil-surl'Estrée: Fayard, 1994.

Foucault, M. O nascimento da clínica. Rio de Janeiro: Forense-Universitária, 1977.

Freud, S. (1956 [1886]). Informe sobre mis estudios en París y Berlín. In: Obras completas (O.C.). Buenos Aires: Amorrortu, 1986. v. I. (1888b). Histeria. O.C., vol. I.

(1893f). Charcot. In: Résultats, idées, problèmes I-1890-1920. Paris: PUF, 1995. (1900a). L'interprétation des rêves. Paris: PUF, 1980.

(1901b). La psychopathologie de la vie quotidienne. Paris: Gallimard, 1997. (1913j). L'intérêt de la psychanalyse. In: Résultats, idées, problèmes I-18901920. Op. cit.

(1913m). Sur la psychanalyse. In: Oeuvres complètes (OCF.P). Directeurs de la

Publication: André Bourguignon e Pierre Cotet, Directeur Scientifique: Jean Laplanche. Paris: PUF, 1998. v. XI.

(1915c). Pulsions et destin des pulsions. OCF.P., 1988. v. XIII.

(1916-17). Leçons d'introduction à la psychanalyse. OCF.P, 2000, vol. XIV. (1920g). Au-delà du principe du plaisir. OCF.P, 1996, v. XV.

(1923a). "Psychanalyse" et "Théorie de la libido". OCF.P, 1991. v. XVI.

(1925d). Autoprésentation. OCF.P, 1992. v. XVII.

(1933a). Nouvelles suite des leçons d'introdution à la psychanalyse, XXXII

Leçon - Angoisse et vie pulsionnelle. OCF.P, 1995. v. XIX.

(1937c). L'analyse avec fin et l'analyse sans fin. In: Résultats, idées, problèmes

- II, 1921-1938. Paris: PUF, 1995.

(1940a). Abrégé de psychanalyse. Paris: PUF, 1985.

(1960a). Correspondance 1873-1939. Paris: Gallimard, 1991.

Fulgencio, L. O abandono da hipnose e a leitura metapsicológica dos sintomas. Revista de Psicanálise Percurso. São Paulo, ano 11, n. 21, 1998.

Apresentação e comentários do documento: convocação para a fundação de uma "Sociedade para a Filosofia Positivista". Revista Internacional de Filosofia e Práticas Psicoterápicas Natureza Humana. São Paulo: EDUC, v. 2, n. 2, 2001a, p. 429-38.

O método especulativo em Freud. Tese de doutorado defendida no Programa 


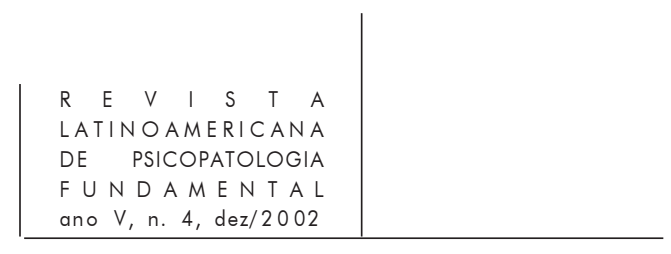

dos Estudos Pós-graduados em Psicologia Clínica da PUC-SP. São Paulo, sob a orientação do Prof. Dr. Zeljko Loparic, 2001b.

LIPPS, T. (1897). O conceito de inconsciente na psicologia. Revista Internacional de Filosofia e Práticas Psicoterápicas Natureza Humana. São Paulo: EDUC, v. 3, n. 2, 2001, p. 335-56.

Loparic, Z. Resolução de Problemas e Estrutura de Teorias em Mach. Cadernos de história da Filosofia da Ciência. Campinas: CLE, v. 6, 1984, p. 35-62.

O conceito de Trieb na filosofia e na psicanálise. In: MACHADO, J. A. T. (org.) Filosofia e psicanálise: um diálogo. Porto Alegre: EDIPCRS, 1999.

Além do inconsciente: sobre a desconstrução heideggeriana da psicanálise de Freud. Revista Internacional de Filosofia e Práticas Psicoterápicas Natureza Humana. São Paulo: EDUC, v. 3, n. 1, 2001a, p. 91-140.

Theodor Lipps: uma fonte esquecida do paradigma freudiano. Revista Internacional de Filosofia e Práticas Psicoterápicas Natureza Humana. São Paulo: EDUC, v. 3, n. 2, 2001b, p. 315-31.

MACH, E. (1905). La conaissance et l'erreur. Paris: Flammarion, 1922.

Mezan, R. Tempo de muda. São Paulo: Companhia das Letras, 1998.

SHAKOw, D. \& RAPAPORT, D. Nineteenth and Early Twentieth Century Background. In: The Influence of Freud on American Psychology. New York: International Universities, Psychological Issues, v. 14, n. 1, Monograph 13, 1964.

\section{Resumos}

Este artículo pretende mostrar qué y cómo Freud reformuló la comprensión de las psicopatologías de su época, al adoptar como guía de investigación el punto de vista dinámico, en cuanto principio metodológico especulativo de valor únicamente heurístico.

Palabras claves: Psicopatología, histeria, dinámica, especulación, heurística

Cet article se propose de montrer comment Freud a reformulé la compréhension des psycopathologies de son époque, en choissant comme guide de sa recherche le point de vue dynamique, entendu comme un principe méthodologique spéculatif qui n'a de valeur qu'heuristique.

Mots clés: Psychopathologie, hysterie, dynamique, spéculation, heuristique

This article shows how Freud altered the understanding of the psychopathologies of his time, using as a research guide the dynamic point of view, as a speculative methodological principal of merely heuristic value.

Key words: Psychopathology, hysteria, speculation, dynamics, heuristic

Versão inicial recebida em maio de 2002

Aprovado para publicação em outubro de 2002 